\title{
Características morfo-agronômicas de cultivares crioulas de feijão comum em dois anos de cultivo
}

\author{
Morpho-agronomic traits of common bean \\ landraces in two growing seasons
}

\author{
Cileide Maria Medeiros Coelho ${ }^{1 *}$; Marcio Zilio²; Clovis Arruda Souza \\ Altamir Frederico Guidolin ${ }^{4}$; David José Miquelluti ${ }^{5}$
}

\begin{abstract}
Resumo
O objetivo deste trabalho foi caracterizar a diversidade de genótipos crioulos de feijão em dois anos de cultivo quanto às características morfoagronômicas. O experimento foi conduzido com 24 genótipos nas safras de 2006/2007 e 2007/2008 no município de Lages - SC, sob delineamento experimental em blocos ao acaso com 3 repetições, em que foram avaliadas 12 características morfológicas e agronômicas. Foi utilizada a técnica de análise multivariada para medir a divergência genética representada pela distância generalizada de Mahalanobis e o agrupamento dos genótipos foi realizado através do método de otimização de Tocher. Entre as 12 características avaliadas, o peso de 100 sementes foi o caráter que apresentou maior contribuição na separação dos genótipos, seguido pelo comprimento da vagem, nos dois anos de cultivo. Os genótipos BAF 3, BAF 37, BAF 42, BAF 55, BAF 57 e BAF 75 apresentaram elevados níveis de produtividade (acima de $4.000 \mathrm{Kg} \mathrm{ha}^{-1}$ ) nos dois anos de cultivo, e podem ser incorporados aos programas de melhoramento da cultura ou indicados para os agricultores.

Palavras-chave: Feijão crioulo, característica morfológica, análise multivariada, germoplasma
\end{abstract}

\begin{abstract}
The objective of this work was to characterize the genetic diversity of landrace beans in two years for morphologic and agronomy characteristics. Twenty four bean (Phaseolus vulgaris L.) genotypes were evaluated during the growing seasons of 2006/2007 and 2007/2008, using the randomized block design with three replications in Lages - SC. The genotypes were analyzed for 12 morphological and agronomic traits. The genotypes were studied using multivariable techniques to measure genetic divergence represented by the generalized distance of Mahalanobis and the genotypes grouping was performed by Tocher's optimization procedure. Among the 12 variables evaluated, the weight of 100 seeds had the highest contribution in the separation of the genotypes followed by the pod length in the two seasons. Genotypes BAF 3, BAF 37, BAF 42, BAF 55, BAF 57 and BAF 75 had high grain yield (around $4,000 \mathrm{Kg} \mathrm{ha}^{-1}$ ) in the two growing seasons and they could be incorporated in the programs of genetic breeding or used in the crop production.
\end{abstract}

Key words: Morphologic characteristic, multivariable analyses, germplasm

${ }_{1}$ Prof ${ }^{a}$ do Departamento de Fitotecnia, Universidade Federal de Santa Catarina, UFSC, Florianópolis-SC. E-mail: cileide@cca. ufsc.br

2 Mestrando em Produção Vegetal da Universidade do Estado de Santa Catarina, UDESC, Lages-SC. E-mail: marciozilio@gmail.com

3 Prof. do Departamento de Agronomia, Universidade do Estado de Santa Catarina, UDESC, Lages-SC. E-mail: souza_clovis@, cav.udesc.br

${ }^{4}$ Prof. do Departamento de Agronomia, Universidade do Estado de Santa Catarina, UDESC, Lages-SC. E-mail: a2afg@cav. udesc.br

${ }_{5}$ Prof. do Departamento de Solos e Recursos Naturais, Universidade do Estado de Santa Catarina, UDESC, Lages-SC. E-mail: a2djm@cav.udesc.br

* Autor para correspondência 


\section{Introdução}

A variabilidade genética do feijão (Phaseolus vulgaris L.) encontrada nos bancos de germoplasma deve ser caracterizada para indicar genótipos mais promissores para os trabalhos de melhoramento e também para melhorar as condições dos agricultores, permitindo o uso racional destes genótipos na agricultura familiar. No caso do feijão, este último aspecto é particularmente importante por se caracterizar como uma cultura de pequena a média propriedade, e de agricultura familiar, a qual representa $67 \%$ de todo feijão do Brasil (EMBRAPA, 2004). Em Santa Catarina a agricultura familiar também responde por $67 \%$ do feijão produzido no estado (ICEPA, 2004).

A utilização de variedades melhoradas e uniformes é uma exigência de mercado, atende às necessidades atuais de aumento da produção de alimentos e gera uma intensa pressão negativa no uso de genótipos crioulos já adaptados para as condições de produção do agricultor. O conhecimento da diversidade genética existente entre esses genótipos é fundamental para o uso correto dos recursos genéticos (LOARCE; GALLEGO; FERRER,1996; ELIAS et al., 2007; GUIMARÃES et al., 2007).

As características morfoagronômicas em feijão, como estatura da planta, número de nós, número de ramos, número de vagens por planta, número de sementes por vagem, podem ser altamente influenciadas pelas variações do ambiente, o que resulta em produtividade média baixa e instável ao longo dos anos (PIANA et al., 1999). Este fato é especialmente observado em feijões crioulos, pois possuem uma ampla base genética, em que as respostas na morfologia e nos caracteres do rendimento podem ser alterados por déficit hídrico, grandes oscilações na temperatura, falta de luminosidade e excesso de umidade.

A interação de cultivares com o ambiente é um dos grandes desafios dos programas de melhoramento. Este componente pode tornar onerosa e lenta a seleção de genótipos para determinadas características. Portanto a avaliação dos genótipos deve ser realizada em diversos locais, permitindo a recomendação de cultivares para ambientes específicos e/ou gerais.

Além da interação genótipo x ambiente ocorrer entre os locais de uma região, no mesmo ano de cultivo, a presença de interação também é esperada em cada local, entre anos. Esse efeito pode alterar o agrupamento dos genótipos, independente do método de agrupamento utilizado (CARGNELUTTI FILHO et al., 2008). Portanto, as avaliações do efeito do ano sobre os genótipos são de fundamental importância para o conhecimento de como a planta responde aos diferentes anos de cultivo, no mesmo ambiente, principalmente quanto às características morfológicas e agronômicas. A inclusão de novos ambientes poderá alterar a classificação dos genótipos e novos experimentos serão necessários para aumentar a confiabilidade da seleção.

Através das análises de morfologia da planta é possível definir com maior eficiência os genótipos promissores para trabalhos de melhoramento, as variáveis que são relevantes para o estudo da diversidade genética e os caracteres que não contribuem para a separação dos genótipos.

Outros autores (RODRIGUES et al., 2002; COELHO et al., 2007; ELIAS et al., 2007) caracterizaram a diversidade genética de genótipos crioulos, através da morfologia e dos componentes do rendimento, para a seleção de caracteres de interesse para os estudos de melhoramento. Contudo, essas avaliações foram realizadas em apenas um ano de cultivo. Neste sentido, observase a importância das avaliações serem realizadas em mais anos no mesmo local, e com os mesmos genótipos, obtendo-se, assim, maior certeza sobre os caracteres de relevância na diversidade genética. Essas avaliações não podem ser extrapoladas para outros locais, devido às diferenças entre ambientes.

A discriminação dos genótipos de um banco de germoplasma podem ser feita através de análises multivariada, contudo é necessário escolher 
os descritores mais relevantes (PEREIRA; VENCOVSKY; CRUZ, 1992; AMARAL JÚNIOR, 1994; RODRIGUES et al., 2002; COELHO et al., 2007). Quando diversos caracteres de diferentes genótipos são medidos simultaneamente, aos pares, as distâncias de Mahalanobis $\left(\mathrm{D}^{2}\right)$ podem ser tomadas como estimativas de diversidade genética entre eles. Essa diversidade é obtida segundo diferenças fisiológicas, morfológicas e agronômicas, avaliadas a partir de um grupo de genótipos (ELIAS et al., 2007).

Entre os métodos propostos para análise de agrupamento, observa-se que os mais utilizados nos programas de melhoramento de plantas são os hierárquicos e os de otimização de Tocher (ELIAS et al., 2007). No método de Tocher adota-se o critério de que a média das medidas de dissimilaridade dentro de cada grupo deve ser menor que as distâncias médias entre quaisquer grupos.

O objetivo deste trabalho foi caracterizar a diversidade genética nos genótipos de feijão crioulo da Universidade do Estado de Santa Catarina (UDESC), em dois anos de cultivo (2006/2007 e 2007/2008), quanto às características agronômicas e componentes de rendimento, e compará-las com as cultivares comerciais recomendadas para a região.

\section{Material e Métodos}

O experimento foi conduzido a campo com 24 genótipos, sendo 20 genótipos crioulos e 4 cultivares comerciais, pertencentes ao Banco Ativo de Feijão (BAF) da Universidade do Estado de Santa Catariana (UDESC). Este trabalho foi realizado nas safras agrícolas de 2006/2007 e 2007/2008 (anos 1 e 2 respectivamente), em Lages, no Planalto Sul de Santa Catarina, com as seguintes coordenadas geográficas $27^{\circ} 52^{\prime} 30^{\prime \prime} \mathrm{S}$ e $50^{\circ} 18^{\prime} 20^{\prime \prime}$ $\mathrm{O}$, com altitude média de $930 \mathrm{~m}$, e caracterizado pela presença de verões brandos com chuvas bem distribuídas (EPAGRI, 2008).
Os genótipos utilizados foram o BAF 3, 4, 7, $11,13,23,26,37,39,41,42,44,46,50,55,57$, $58,60,68,75,111,112,115,121$, sendo as quatro cultivares comerciais BAF 111 (Pérola), BAF 112 (IPR-88-Uirapurú), BAF 115 (BRS-Valente) e BAF 121 (Iapar 81) (Tabela 1).

O delineamento experimental foi de blocos inteiramente casualizados, com três repetições, em parcelas de quatro linhas de três metros, com 15 sementes por metro, sendo as duas linhas externas consideradas como bordaduras e a área útil as duas linhas internas, excluindo 0.5 metros das extremidades. A adubação de base foi realizada junto às linhas, previamente à semeadura, segundo análise do solo e recomendações descritas em publicações da Comissão de Química e Fertilidade do Solo CQFS-RS/SC (2004). A adubação de cobertura foi realizada duas vezes, nos estádios de três e cinco trifólios (V4 a V4-5), utilizando-se uma dosagem de $30 \mathrm{Kg}$ de $\mathrm{N}$ por hectare em cada aplicação. O controle de plantas daninhas e de pragas foi feito de acordo com as necessidades, utilizando-se os produtos químicos recomendados para a cultura.

Os genótipos foram avaliados após a colheita quanto à altura de inserção da primeira vagem, número médio de lóculos por vagem, espessura do caule, número de racemos com vagem por planta, número de ramos com vagem, comprimento da vagem, espessura da vagem, número de nós, peso de 100 sementes, número de vagens por planta, número de sementes por vagem e a produtividade.

A produtividade de grãos foi estimada em $\mathrm{Kg}$ $h^{-1}$, em razão do rendimento de grãos na área útil de cada parcela. Para a obtenção das características agronômicas foram coletadas ao acaso 10 plantas da área útil de cada parcela experimental. $\mathrm{O}$ peso de 100 sementes foi obtido de plantas da área útil da parcela. 
Tabela 1. Número de identificação, nome comum, origem, e cor da semente dos genótipos do Banco Ativo de Feijão do CAV- UDESC.

\begin{tabular}{|c|c|c|c|}
\hline Número do genótipo & Nome do genótipo & Origem & Cor da semente \\
\hline BAF 03 & Manchinha & Palmitos - SC & Branca e Vermelha \\
\hline BAF 04 & Amendoim Lages & Lages - SC & Vermelha \\
\hline BAF 07 & Preto Lages & Lages - SC & Preta \\
\hline BAF 11 & Manchinha & Lages - SC & Preta \\
\hline BAF 13 & Taquara & Caxambú do Sul-SC & Preta \\
\hline BAF 23 & Preto Chapecó & Chapecó - SC & Preta \\
\hline BAF 26 & Minas Preto & Palmitos - SC & Preta \\
\hline BAF 37 & Variação do Corrente & CENA-Piracicaba - SP & Carioca \\
\hline BAF 39 & Sem Nome & Bom Jardim da Serra - SC & Branca e Vermelha \\
\hline BAF 41 & Rosinha & Bom Jardim da Serra - SC & Preta \\
\hline BAF 42 & Feijão Vagem Branca & Capão Alto - SC & Preta \\
\hline BAF 44 & Vermelho & Capão Alto - SC & Vermelha \\
\hline BAF 46 & Sem Nome & Lages - SC & Preta \\
\hline BAF 50 & Carioca Brilhante & Lebon Regis - SC & Carioca \\
\hline BAF 55 & Preto & Cunha Porá - SC & Preta \\
\hline BAF 57 & Preto & Cunha Porá - SC & Preta \\
\hline BAF 58 & Sem Nome & Cunha Porá - SC & Vermelha \\
\hline BAF 60 & Preto 60 Dias & Lebon Regis - SC & Preta \\
\hline BAF 68 & Vermelho & Lagoa Vermelha - RS & Vermelha \\
\hline BAF 75 & Serrano & Formigueiro - RS & Preta \\
\hline BAF 111 & Pérola & Lages - SC & Carioca \\
\hline BAF 112 & IPR-88-Uirapurú & Lages - SC & Preta \\
\hline BAF 115 & BRS-Valente & Lages - SC & Preta \\
\hline BAF 121 & Iapar 81 & Lages - SC & Carioca \\
\hline
\end{tabular}

Banco Ativo de Feijão (BAF) da Universidade do Estado de Santa Catariana (UDESC).

As análises estatísticas foram realizadas através do programa GENES (CRUZ, 1997). Realizaramse análises de variância univariada para todas as variáveis estudadas nos dois anos considerados. Após, as médias das variáveis para cada genótipo foram comparadas pelo teste de Scott-Knott, a 5\% de probabilidade em cada ano de cultivo.

Para a determinação da divergência genética entre os genótipos utilizou-se a distância generalizada de Mahalanobis (SINGH, 1981). E para o agrupamento foi utilizado o método de otimização de Tocher (RAO, 1952).

\section{Resultados e Discussão}

A análise conjunta dos dados revelou efeito significativo de genótipo e da interação entre genótipo $\mathrm{x}$ ano, no entanto, o efeito significativo de ano foi observado apenas para alguns caracteres (Tabela 2). Diante destes resultados, realizou-se o desdobramento da interação genótipo $\mathrm{x}$ ano. 
Tabela 2. Análise de variância conjunta dos 12 caracteres de importância agronômica, nas 24 cultivares crioulas de feijão, nos dois anos de cultivo (2006/2007 e 2007/2008).

\begin{tabular}{lcccc}
\hline \multirow{2}{*}{ Caracteres } & \multicolumn{3}{c}{ Quadrado médio } & \multirow{2}{*}{ CV (\%) } \\
\cline { 2 - 4 } & Genótipos & Ano & Genótipo x Ano & \\
\hline Produtividade $\left(\mathrm{Kg} \mathrm{ha}^{-1}\right)$ & $3.479 .554,69^{*}$ & $915.263,69$ & $1.331 .905,16^{*}$ & 24,80 \\
Espessura do caule (mm) & $2,87^{*}$ & $16,48^{*}$ & $1,57^{*}$ & 10,95 \\
Altura de inserção da primeira vagem (cm) & $32,92^{*}$ & $105,85^{*}$ & $13,59^{*}$ & 15,74 \\
Número de racemos com vagem & $23,91^{*}$ & 10,68 & $15,85^{*}$ & 24,31 \\
Número de ramos com vagem & $2,30^{*}$ & $120,54^{*}$ & $2,23^{*}$ & 22,09 \\
Número de nós & $21,86^{*}$ & 0,12 & $3,39^{*}$ & 12,10 \\
Número de vagens por planta & $89,83^{*}$ & 38,42 & $36,63^{*}$ & 25,53 \\
Comprimento da vagem (cm) & $3,08^{*}$ & $8,49^{*}$ & $0,47^{*}$ & 5,27 \\
Espessura da vagem (mm) & $2,82^{*}$ & 0,10 & $1,96^{*}$ & 12,12 \\
Número de sementes por vagem & $2,25^{*}$ & 0,25 & $0,46^{*}$ & 9,68 \\
Número de lóculos por vagem & $2,00^{*}$ & $4,07^{*}$ & $0,47^{*}$ & 7,83 \\
Peso de 100 sementes (g) & $218,37^{*}$ & $99,09^{*}$ & $7,60^{*}$ & 6,48 \\
\hline
\end{tabular}

*Significativo pelo teste $\mathrm{F}$ a $5 \%$ de probabilidade de erro.

Ao realizar o desdobramento da interação genótipo x ano, verificou-se diferença significativa entre os genótipos para a maioria dos caracteres avaliados, com exceção do número de ramos com vagem nos dois anos, número de racemos com vagem e altura de inserção da primeira vagem no ano
1 e espessura da vagem no ano 2, pelo teste $\mathrm{F}$ a $5 \%$ de significância (Tabela 3). Esta diferença mostra a presença de diversidade genética e sua resposta diferencial para cada ano de cultivo, indicando efeito do ano de cultivo sobre cada genótipo para as avaliações realizadas.

Tabela 3. Análise de variância univariada dos 12 caracteres de importância agronômica nas 24 cultivares crioulas de feijão.

\begin{tabular}{|c|c|c|c|c|}
\hline \multirow{3}{*}{ Caracteres } & \multicolumn{2}{|l|}{ Ano 1} & \multirow{3}{*}{ Média geral } & \multirow{3}{*}{ CV $(\%)$} \\
\hline & \multicolumn{2}{|c|}{ Quadrado médio } & & \\
\hline & Genótipos & Erro & & \\
\hline Produtividade $\left(\mathrm{Kg} \mathrm{ha}^{-1}\right)$ & $2.785 .781,93 *$ & $466.860,30$ & $3.038 .230,00$ & 22,49 \\
\hline Espessura do caule (mm) & $1,36^{*}$ & 0,49 & 5,95 & 11,73 \\
\hline Altura de inserção da primeira vagem $(\mathrm{cm})$ & 9,59 & 5,62 & 14,33 & 16,54 \\
\hline Número de racemos com vagem & 12,45 & 9,71 & 11,25 & 27,69 \\
\hline Número de ramos com vagem & 2,63 & 1,43 & 5,73 & 20,90 \\
\hline Número de nós & $9,70 *$ & 2,60 & 11,03 & 14,61 \\
\hline Número de vagens por planta & $43,87^{*}$ & 19,6 & 16,58 & 26,70 \\
\hline Comprimento da vagem $(\mathrm{cm})$ & $2,37^{*}$ & 0,18 & 9,82 & 4,38 \\
\hline Espessura da vagem (mm) & $1,25^{*}$ & 0,43 & 8,52 & 7,69 \\
\hline Número de sementes por vagem & $1,28^{*}$ & 0,21 & 5,20 & 8,75 \\
\hline Número de lóculos por vagem & $1,14^{*}$ & 0,17 & 6,06 & 6,77 \\
\hline Peso de 100 sementes (g) & $100,80 *$ & 5,03 & 27,48 & 8,16 \\
\hline
\end{tabular}




\begin{tabular}{lcccc}
\hline \multicolumn{1}{c}{ Caracteres } & \multicolumn{2}{c}{ Ano 2 } & & \\
\cline { 2 - 4 } & \multicolumn{2}{c}{ Quadrado médio } & Média geral & \multirow{2}{*}{ CV (\%) } \\
\cline { 2 - 4 } & Genótipos & Erro & & \\
\hline Produtividade $\left(\mathrm{Kg} \mathrm{ha}^{-1}\right)$ & $2.025 .677,92^{*}$ & $620.751,10$ & $2.842,94$ & 27,71 \\
Espessura do caule (mm) & $3,09^{*}$ & 0,51 & 6,78 & 10,49 \\
Altura de inserção da primeira vagem (cm) & $36,92^{*}$ & 5,67 & 16,43 & 14,49 \\
Número de racemos com vagem & $22,56^{*}$ & 6,04 & 11,92 & 20,61 \\
Número de ramos com vagem & 0,89 & 0,73 & 3,49 & 24,47 \\
Número de nós & $14,41^{*}$ & 0,98 & 11,10 & 8,91 \\
Número de vagens por planta & $82,59^{*}$ & 18,88 & 17,85 & 24,35 \\
Comprimento da vagem (cm) & $1,18^{*}$ & 0,28 & 9,22 & 5,76 \\
Espessura da vagem (mm) & 2,95 & 1,68 & 8,58 & 15,10 \\
Número de sementes por vagem & $1,22^{*}$ & 0,32 & 5,31 & 10,74 \\
Número de lóculos por vagem & $1,15^{*}$ & 0,32 & 6,47 & 8,80 \\
Peso de 100 sementes (g) & $122,58^{*}$ & 2,01 & 29,51 & 4,81 \\
\hline
\end{tabular}

Ano 1, safra 2006/2007; Ano 2, safra 2007/2008. *Significativo pelo teste F a 5\% de probabilidade de erro.

Através da análise discriminante linear para cada ano, verificou-se a contribuição das variáveis em relação à variação total, com o objetivo de indicar a contribuição relativa dos caracteres avaliados para diversidade.

No ano 1, a maior contribuição relativa para a separação dos genótipos foi o peso de 100 sementes $(29,49 \%)$, seguido pelo comprimento da vagem $(23,73 \%)$, número de sementes por vagem
(16,37\%), número de lóculos por vagem $(9,98 \%)$, produtividade $(7,91 \%)$, o que representou um total de $87,48 \%$. Tais percentuais obtidos na contribuição demonstraram que 5 variáveis analisadas, de um total de 12 , contribuíram de forma específica na separação dos genótipos. As variáveis espessuras da vagem $(4,99 \%)$, espessura do caule $(3,55 \%)$, número de nós $(3,42 \%)$ e o número de vagens por planta $(0,57 \%)$, contribuíram de forma menos significativa na separação dos genótipos (Tabela 4).

Tabela 4. Contribuição relativa dos caracteres para diversidade das cultivares crioulas de feijão (SINGH, 1981) através da distância generalizada de Mahalanobis.

\begin{tabular}{lll}
\hline \multirow{2}{*}{\multicolumn{1}{c}{ Variável }} & \multicolumn{1}{c}{ Ano 1 } & \multicolumn{1}{c}{ Ano 2 } \\
\cline { 2 - 3 } & \multicolumn{1}{c}{ Valor em \% } & Valor em \% \\
\hline Produtividade & 7,91 & 3,38 \\
Espessura do caule & 3,55 & 5,1 \\
Número de nós & 3,42 & 12,94 \\
Número de vagens por planta & 0,57 & 10,48 \\
Comprimento da vagem & 23,73 & 13,53 \\
Número de sementes por vagem & 16,37 & 9,08 \\
Número de lóculos por vagem & 9,98 & 2,08 \\
Peso de 100 sementes & 29,49 & 32,83 \\
Espessura da vagem & 4,99 & - \\
Altura de inserção da primeira vagem & - & 7,77 \\
Número de racemos com vagem & - & 2,79 \\
\hline
\end{tabular}

Ano 1, safra 2006/2007; Ano 2, safra 2007/2008. 
Os caracteres que não contribuíram para a separação dos genótipos foram a altura de inserção da primeira vagem, número de ramos com vagem e número de racemos com vagem. Esses caracteres apresentam valores semelhantes nos genótipos avaliados, por isso não contribuíram para a discriminação dos genótipos e não são indicados nos trabalhos de caracterização da diversidade. Este resultado concorda com o trabalho de Coelho et al. (2007), em que esses três caracteres também apresentaram efeito de supressão na separação dos genótipos avaliados na safra 2005/06.

Para o ano 2, o peso de 100 sementes foi a característica que teve a maior contribuição para a divergência genética, com 32,83\%, seguida por comprimento da vagem $(13,53 \%)$, número de nós $(12,94 \%)$, número de vagem por planta $(10,48 \%)$, número de sementes $(9,08 \%)$, altura de inserção da primeira vagem $(7,77 \%)$, espessura do caule $(5,10 \%)$, produtividade $(3,38 \%)$, número de racemos com vagem (2,79\%), seguido pelo caractere que menos contribuiu para a separação dos genótipos, número de lóculos por vagem com 2,08\% (Tabela 4). Com a análise dos percentuais obtidos na contribuição, observou-se que 10 variáveis contribuíram para a separação dos genótipos. Apenas 2 caracteres não contribuíram para a separação dos genótipos no segundo ano (espessura da vagem e número de ramos com vagem). Resultado semelhante foi encontrado por Coelho et al. (2007), em que o número de ramos com vagem não apresentou efeito na separação dos genótipos.

O caractere que não contribuiu para a separação dos genótipos, nos dois anos de cultivo, foi o número de ramos com vagem. Este caractere é pouco relevante em estudos de divergência genética e identificação de duplicidade na coleção de germoplasma.

O peso de 100 sementes foi o caractere que nos dois anos de cultivo apresentou elevado poder discriminador e, portanto é altamente importante nos estudos de divergência genética, como previamente observado por outros autores (SINGH, 1981; FONSECA; SILVA, 1999; COELHO et al., 2007; ELIAS et al., 2007), possivelmente por ser um caráter de herança qualitativa, pouco influenciado pelo ambiente e controlado por poucos genes (RAMALHO; SANTOS; ZIMMERMANN, 1993).

$\mathrm{Na}$ Tabela 3, pode ser observado que alguns caracteres tiveram contribuição na separação dos genótipos em um dos anos e no outro não. Além disso, os caracteres não apresentaram a mesma estimativa da contribuição relativa ou na importância discriminante nos dois anos.

As respostas diferenciadas dos genótipos ao ambiente já foram citadas por outros autores como um fator importante. Segundo Cargnelutti Filho et al. (2008) e Bertan et al. (2006), os agrupamentos de genótipos com base em apenas um ano podem fornecer informações equivocadas, por não considerarem a variabilidade ambiental entre anos dentro do mesmo local.

A partir do cálculo da distância generalizada de Mahalanobis, foi realizado o agrupamento dos genótipos. O método usado foi pela otimização de Tocher, fundamentado na dissimilaridade, o que possibilitou a distribuição dos 24 genótipos em 8 grupos no ano 1 e em 4 grupos no ano 2 (Tabela 5).

No ano 1, observaram-se dois grandes grupos: grupo I (BAF 7, BAF 26, BAF 37, BAF 41, BAF 42, BAF 44, BAF 55, BAF 60, BAF 111 e BAF 112), grupo II (BAF 4, BAF 39, BAF 57 BAF 58 e BAF 68). No ano 2, os genótipos foram agrupados também em dois grandes grupos: grupo I (BAF 3, BAF 7, BAF 13, BAF 26, BAF 37, BAF 41, BAF 44, BAF 50, BAF 55, BAF 60, BAF 75, BAF 111, BAF 112, BAF 115 e BAF 121), grupo II (BAF 4, BAF 11, BAF 39, BAF 46, BAF 57, BAF 58 e BAF 68). 
Tabela 5. Agrupamento das cultivares crioulas de feijão pelo método de otimização de Tocher.

\begin{tabular}{ll}
\hline & \multicolumn{1}{c}{ Ano 1 } \\
\hline Grupos & BAFs \\
\hline I & $7,26,37,41,42,44,55,60,111$ e 112 \\
II & $4,39,57,58$ e 68 \\
III & 11 e 46 \\
IV & 50 e 121 \\
V & 13 e 75 \\
VI & 115 \\
VII & 3 \\
VIII & 23 \\
\hline & \multicolumn{1}{l}{ Ano 2 } \\
\hline Grupos & BAFs \\
I & $3,7,13,26,37,41,44,50,55,60,75,111$, \\
II & 112,115 e 121 \\
III & $4,11,39,46,57,58$ e 68 \\
IV & 23 \\
\hline
\end{tabular}

Ano 1, safra 2006/2007; Ano 2, safra 2007/2008.

Todos os genótipos do grupo I no ano 1 apresentaram peso de 100 sementes igual ou inferior a 25,65 g. No grupo II todos os genótipos tiveram peso de 100 sementes igual ou superior a $32,99 \mathrm{~g}$. Os valores para esse caractere variaram de 19,11 g a 40,20 g. Segundo Singh (1989), o peso de sementes de feijão pode variar de menos de 15 a 90 g e são agrupadas em pequenas ( $<25 \mathrm{~g})$, médias ( $25 \mathrm{a} 40 \mathrm{~g}$ ) e grandes $(>40 \mathrm{~g})$. No presente trabalho apenas dois genótipos foram classificados como semente grande (BAF 58 e BAF 4).

No ano 2 todos os genótipos do grupo I apresentaram peso de 100 sementes entre 28,61 g a 21,30 g. No grupo II todos os genótipos apresentaram peso de 100 sementes entre $36,27 \mathrm{~g}$ a 43,64 g. Considerando os 24 genótipos avaliados, os valores para peso de 100 sementes variaram de $21,30 \mathrm{~g}$ a 43,64 g. No ano 2 quatro genótipos foram classificados como sementes grandes (BAF 58, BAF 4, BAF 11 e BAF 23), segundo Singh (1989).

Para os demais caracteres no ano 1 (comprimento da vagem, número de sementes por vagem, número de lóculos por vagem, produtividade, espessura da vagem, espessura do caule, número de nós e o número de vagens por planta), e no ano 2 (comprimento da vagem, número de nós, número de vagens por planta, número de sementes, altura de inserção da primeira vagem, espessura do caule, produtividade, número de racemos com vagem e o número de lóculos por vagem), não se observou efeito acentuado na separação dos genótipos. Estes caracteres foram pouco relevantes no estudo de divergência genética e na identificação de duplicidade entre os genótipos do banco de germoplasma.

Nos dois anos de cultivo o número e o genótipo dentro de cada grupo não foram iguais, com exceção dos grupos VIII e III, que apresentaram o mesmo genótipo (BAF 23). A mudança do genótipo, nos grupos de um ano para outro, pode ser resultado da expressão do gene que, dependendo do ano, pode ser diferente.

A produtividade foi uma característica discriminante dos genótipos nos dois anos de cultivo, mas apresentou um pequeno poder de separação. Este caráter poderia apresentar maior percentual de discriminação entre populações mais uniformes em termos de segregação genética relativa ao rendimento de grãos (COELHO et al., 2007).

Contudo, vale salientar que alguns genótipos apresentaram produtividades elevadas nos dois anos de cultivo. Os genótipos BAF 115, BAF 75, BAF 57, BAF 42 e o BAF 55 e os genótipos BAF 112, BAF 115, BAF 37 e BAF 3 apresentaram produtividades acima de $4.000 \mathrm{Kg} \mathrm{ha}^{-1}$, para ambos os anos avaliados.

A produtividade média dos genótipos crioulos em relação aos genótipos melhorados foi inferior nos dois anos de cultivo. Os genótipos crioulos produziram em média $2.946 \mathrm{Kg} \mathrm{ha}^{-1}$ no ano 1 , e $2.618 \mathrm{Kg} \mathrm{ha}^{-1}$ no ano 2, enquanto que as cultivares comerciais produziram $3.496 \mathrm{Kg} \mathrm{ha}^{-1}$ no ano $1 \mathrm{e}$ $3.966 \mathrm{Kg} \mathrm{ha}^{-1}$ no ano 2. Apesar de terem apresentado média geral inferior, os genótipos crioulos BAF 75, BAF 57, BAF 42, BAF 55 BAF 37 e BAF 3 podem ser indicados para serem incorporados em 
programas de melhoramento da cultura em função de apresentarem produtividades acima de 4.000 $\mathrm{Kg} \mathrm{ha}^{-1}$.

\section{Conclusão}

Há significativa divergência entre as vinte cultivares crioulas e entre as quatro cultivares comerciais avaliadas, sendo o peso de 100 sementes o caráter que mais contribuiu para a separação dos genótipos, seguido pelo comprimento da vagem, em ambos anos de cultivo. Tais caracteres que contribuíram na separação dos genótipos devem ser utilizados nos trabalhos de divergência genética e na identificação de duplicidade em bancos germoplasma.

As cultivares crioulas (BAF 3, BAF 37, BAF 42, BAF 55, BAF 57 e BAF 75) apresentaram produtividades acima de $4.000 \mathrm{Kg} \mathrm{ha}^{-1}$, para ambos os anos avaliados, portanto podem ser indicadas para compor cruzamentos nos programas de melhoramento que visem elevadas produtividades.

\section{Agradecimentos}

Os autores agradecem a CAPES (Coordenação de Aperfeiçoamento de Pessoal de Nível Superior) pelo apoio financeiro via PRODOC (Programa de Apoio a Projetos Institucionais), concedido ao autor C.M.M. Coelho.

\section{Referências}

AMARAL JÚNIOR, A. T. Análise multivariada e isoenzimática da divergência genética entre acessos de moranga (Cucurbita maxima Duchesne). 1994. Dissertação (Mestrado em Genética e Melhoramento) Departamentos de Biologia Geral, Fitotecnia e Zootecnia. Universidade Federal de Viçosa, Viçosa, MG.

BERTAN, I.; CARVALHO, F. I. F.; OLIVEIRA, A. C.; VIEIRA, E. A.; HARTWIG, I.; SILVA, J. A. G.; SHIMIDT, D. A. M.; VALÉRIO, I. P.; BUSATO, C. C.; RIBEIRO, G. Comparação de métodos de agrupamento na representação da distância morfológica entre genótipos de trigo. Revista Brasileira de Agrociência, Pelotas, v. 12, n. 3, p. 279-286, jul./set. 2006.

CARGNELUTTI FILHO, A.; RIBEIRO, N. D.; REIS, R. C. P.; SOUZA, J. R.; JOST, E. Comparação de métodos de agrupamento para o estudo da divergência genética em cultivares de feijão. Ciência Rural, Santa Maria, v. 38 , n. 8, p. 2138-2145, nov. 2008.

COELHO, C. M. M.; COIMBRA, J. L. M.; SOUZA, C. A.; BOGO, A.; GUIDOLIN, A. F. Diversidade genética em acessos de feijão (Phaseolus vulgaris L.). Ciência Rural, Santa Maria, v. 37, n. 5, p. 1241-1247, set./out. 2007.

COMISSÃO DE QUÍMICA E FERTILIDADE DO SOLO. Manual de adubação e de calagem para os estados do Rio Grande do Sul e Santa Catarina. 10. ed. Porto Alegre: SBCS, Núcleo Regional Sul/UFRGS, 2004. 400 p.

CRUZ, C. D. Programa genes: aplicativo computacional em genética e estatística. Viçosa, MG: UFV, 1997.

ELIAS, H. T.; VIDIGAL, M. C. G.; GONELA, A.; VOGT, G. A.. Variabilidade genética em germoplasma tradicional em feijão preto em Santa Catarina. Pesquisa Agropecuária Brasileira, Brasília, v. 42, n. 10, p. 14431449, out. 2007.

EMPRESA BRASILEIRA DE PESQUISA AGROPECUÁRIA - EMBRAPA. Pesquisa $e$ desenvolvimento em agricultura familiar na embrapa arroz e feijão. Santo Antônio de Goiás: Embrapa Arroz e Feijão, 2004. 16 p.

EPAGRI. Atlas climatológico do Estado de Santa Catarina. 2008. Disponível em: <http:://www.ciram. epagri.rct-sc.br>. Acesso em: 20 mar. 2008.

FONSECA, J. R.; SILVA, H. T. da. Identificação de acessos de feijão por meio de técnicas multivariadas. Pesquisa Agropecuária Brasileira, Brasília, v. 34, n. 3, p. 409-414, mar. 1999.

GUIMARÃES, W. N. R.; MARTINS, L. S. S.; SILVA, E. F.; FERRAZ, G. M. G.; OLIVEIRA, F. J. Caracterização morfológica e molecular de acessos de feijão-fava (Phaseolus lunatus L.). Revista Brasileira de Engenharia Agrícola e Ambiental, Campina Grande, v. 11, n. 1, p. 3745, jan./fev. 2007.

ICEPA. Sintese anual da agricultura de Santa Catarina: 2003-2004. Florianópolis: Instituto Cepa, 2004. 377 p.

LOARCE, Y.; GALLEGO, R.; FERRER, E. A comparative analysis of the genetic relationship between rye cultivars using RFLP and RAPD markers. Euphytica, Wageningen, v. 88, n. 2, p. 107-115, 1996. 
PEREIRA, A. V.; VENCOVSKY, R.; CRUZ, C. D. Selection of botanical and agronomical descriptors for the characterization of cassava (Manihot esculenta Crantz) germoplasm. Revista Brasileira de Genética, Ribeirão Preto, v. 15, n. 1, p. 115-124, 1992.

PIANA, C. F. B.; ANTUNES, I. F.; SILVA, J. G. C.; SILVEIRA, E. P. Adaptabilidade e estabilidade do rendimento de grãos de genótipos de feijão. Pesquisa Agropecuaria Brasileira, Brasília, v. 34, n. 4, p. 553-564, abr. 1999.

RAMALHO, M.A. P.; SANTOS, J. B.; ZIMMERMANN, M. J. de O. Genética quantitativa de plantas autógamas: aplicações ao melhoramento do feijoeiro. Goiânia: UFG, 1993. $271 \mathrm{p}$.
RAO, R. C. Advanced statistical methods in biometrics research. New York: John Wiley and Sons, 1952. 390 p.

RODRIGUES, L. S.; ANTUNES, I. F.; TEIXEIRA, M. G.; SILVA, J. B. Divergência genética entre cultivares locais e cultivares melhoradas de feijão. Pesquisa Agropecuária Brasileira, Brasília, v. 37, n. 9, p. 12751284, set. 2002.

SINGH, D. The relative importance of characters affecting genetic divergence. Indian Journal of Genetics \& Plant Breeding, New Delhi, v. 41, n. 2, p. 237-245, 1981.

SINGH, S. Patterns of variation in cultivated common bean (Phaseolus vulgaris, Fabaceae). Economic Botany, New York, v. 43, n. 1, p. 39-57, 1989. 